\title{
Does High Self-Efficacy in Adolescents Minimize Cyber Bullying Behaviour?
}

\author{
Adem Peker $^{1}{ }^{\oplus}$, Yuksel Eroglu ${ }^{2}$ (), Melike Nebioglu Yildiz ${ }^{3}$ \\ ${ }^{1}$ Atatürk University Kazim Karabekir Faculty of Education, Deparment of Educational Science, Discipline of Guidance Psychological Counseling, Yoncalik Campus, Erzurum, Turkey. \\ ${ }^{2}$ Afyon Kocatepe University, Deparment of Educational Science, Discipline of Guidance Psychological Counseling Ahmet Necdet Sezer Campus Faculty of Education, Afyonkarahisar, Turkey. \\ ${ }^{3}$ Mersin University Faculty of Medicine Department of Mental Health and Diseases, Mersin, Turkey.
}

Correspondence Author: Adem Peker

E-mail: adem.peker@atauni.edu.tr

Received: $18.01 .2021 \quad$ Accepted: 25.03 .2021

\begin{abstract}
Objective: This study aimed to explain the moderation role of self-efficacy in the relationship between cyber victimization and cyber bullying. Methods: A total of 340 high school students participated in the study aged between 14 and 18 years. Research data was obtained by the Cyber Bullying and Internet Aggression Survey Scale, and the Self-Efficacy Scale. Correlation analysis was performed to determine the relationships between variables in the study. Hierarchical regression analysis based on the Hayes method was used to test the moderating effects in the study.

Results: As a result of the research, it was found that $42 \%$ of the participants were exposed to cyber bullying and $35 \%$ engaged in cyber bullying. The research revealed that there is a moderate, positive and significant relationship between cyber victimization and cyber bullying. As a result of moderating analysis, it was observed that self-efficacy affects the relationship between cyber victimization and cyber bullying.

Conclusion: The results indicate that a decrease in self-efficacy leads to increased cyber bullying behaviour, while an increase in self-efficacy decreases cyber bullying behaviour after cyber victimization. From this point of view, carrying out studies to increase the self-efficacy levels of students in schools will reduce cyber bullying.
\end{abstract}

Keywords: Cyber victimization, cyber bullying, self-efficacy, moderation

\section{INTRODUCTION}

The use of new technological tools such as computers, tablets, and smartphones is intensive in education, business and leisure._These tools have benefits such as allowing access to information, communication with other people, for initiating and conducting interpersonal relationships, and organizing leisure activities (1). Adolescents especially use these technological tools for academic activities, establishing friendships and accessing information._Therefore, adolescents may spend most of the day using technological tools. However, this intensive use may negatively affect the spiritual world of adolescents (2).

One of the negative consequences of new technologies is cyber bullying._Cyber bullying is the use of technological tools to harm others (3). The rapidly increasing use of electronic communication tools in the last decade has led to a new form of bullying (4).

Islam et al (5) determined that about $12 \%$ of adolescents are involved in cyber bullying. Lapierre and Dane (1) found that $7.4 \%$ of adolescents engaged in cyber bullying, while Modecki et al (6) found that about $17 \%$ of adolescents were cyber bullying. Hemphil et al (7) reported that $23 \%$ of adolescents engage in cyber bullying. Jadambaa et al (8) reported cyber bullying behaviour in $5 \%$ of adolescents.

Studies revealed that cyber bullying has various adverse effects on victims, such as depressive mood, high level of loneliness, disappointment and grief, and difficulties with academic learning $(9,10)$. Studies conducted in recent years reveal that people with mental health problems are more likely to engage in cyber bullying behaviour $(11,12)$. Cyber bullying and cyber victimization were found to be associated with concepts such as depression, anxiety, and self-esteem (13)._Moreover, it is stated that cyber bullying affects social cohesion and well-being at school (14).

\subsection{Relationship Between Cyber Victimization and Cyber Bullying}

Recent research have shown that one of the strongest predictors of cyber bullying behaviour is for someone to experiencecyberbullying(15). Numerous studies show strong correlations between cyber victimization and continuation ( $r$ $=.50$ to .60$)(16,17)$. Leung et al $(18)$ revealed that there 
is a significant relationship between cyber victimization and cyber bullying $(r=.65)$, while Quintana-Orts and Rey (19) reached the same conclusion ( $r=.57)$. Hood and Duffy (20) also point to a significant relationship between cyber victimization and cyber bullying $(r=.55)$. An analysis of studies conducted in Turkey show that the relationship between cyber victimization and cyber bullying varies between .27 and $.70(21, r=.27 ; 22, r=.48 ; 23, r=.49$ for females, $r=.52$ for males; $24, r=.46 ; 25, r=.70)$.

\subsection{Self-Efficacy and Cyber Bullying}

Self-efficacy is an individual's belief in their capacity to organize actions, cognitive skills, and motivation required to fulfil an undertaking with success (26). According to Bandura (27), self-efficacy is related to a person's own perceptions, and their belief in their capability to organize a result they want, and achieve it with success. The more individuals believe they can treat others offensively, the more probable it is that they will act outrageously and brutally (28). In addition, Erath et al., (29) state that low self-efficacy may cause victimization of individuals. Trompeter et al. (30) revealed that coping self-sufficiency is related to cyber victimization. Bussey et al. (31) showed that cyber bullying, defined as an individual's belief in the competence to engage in cyber bullying, is associated with self-efficacy and cyber bullying. Heiman et al. (32) reported that students exposed to the cyber bullying had lower self-efficacy than students not exposed to cyber bullying.

\subsection{Current Study}

This study is consistent with the results of previous studies $(33,34)$, leadingtotheexpectationofasignificantrelationship between experiencing cyber bullying and cyber bullying behaviour. Furthermore, it is considered that self-efficacy will explain the relationship between cyber victimization and cyber bullying in this study. It is predicted that the positive relationship between cyber-victimization and cyber bullying is going to be weaker for those with high self-efficacy compared to those with low self-efficacy particularly. In line with this, the current research aims to examine the moderating role of self-efficacy in the association between cyber victimization and cyber bullying.

\section{METHOD}

\subsection{Study Group}

The sample group in the study consisted of 340 high school students attending four different state schools in Erzurum province, Turkey. Of the students, $45.9 \%(n=156)$ were female, and $54.1 \%$ were male $(n=184)$. Students participating in the study were aged between 14 and 18 years, with the average age of 15.7 years. Among the students, $24.7 \%(n=84)$ were in 9th grade, $32.9 \%(n=112)$ were in 10 th grade, $28.8 \%(n=98)$ were in 11 th grade, and $13.5 \%(n=46)$ were in 12 th grade.
According to the findings of the research, it was determined that $34.6 \%$ of the students exhibited cyberbullying behaviors and $42.1 \%$ experienced cyber victimization.

The study was conducted between 1-30 April 2020, after ethical approval (30 March 2020). Scales provided via an electronic link. Snowball sampling method was used to determine the participants to participate in the study. The scales prepared online were first given to a student and they were asked to communicate the scale to others using social networks.

\subsection{Measures}

2.2.1. Self-efficacy scale for children:_The Self-Efficacy Scale for Children was developed by Muris (35). Çelikkaleli et al. (35) conducted the adaptation study of the scale into Turkish. The scale consists of 21 items, and 3 sub-dimensions: academic, social, and emotional self-efficacy. As a result of analysis of the scale's internal consistency reliability, the overall coefficient was determined as .86, while the coefficients for academic, social, and emotional self-efficacy were determined as .84, .64 and .78, respectively. Higher scores obtained from the scale signify high levels of self-efficacy in individuals. In this study, the scale was evaluated as the total score.

\subsubsection{Cyber bullying and internet aggression survey scale} (CIASS): In order to determine the cyber victimization and cyber bullying behaviour of students participating in the study, the scale developed by Hinduja and Patchin (36), and adapted to Turkish by Özdemir and Akar (37) was used. The scale consists of 8 items, and two separate forms: cyber victimization and cyber bullying. The internal consistency reliability coefficient was found to be .79 for cyber victimization, and .94 for cyber bullying. High scores obtained from the scale indicate high levels of cyber victimization and cyber bullying.

\subsection{Data Collection Process}

As there was no in-person education at schools due to COVID-19, data were collected online. Hence, the online data collection scales were prepared using Google Forms and sent to the participants. Moreover, informed consent was obtained from individuals who accepted participation in the study before they completed the scales. It was ensured that only volunteers were included in the study. Additionally, individuals were informed that they may stop completing the scales whenever they want, and that the results would be kept confidential. The online data collection process was completed within 30 days. The collected data online were analysed in a computer environment. As it is not possible to move to the next question without marking an answer during the online application, there was no incomplete data in the study. As a result, 350 people completed the scales. 


\subsection{Data Analysis}

Before analysis of the data, the levels of discrepancy and normality were examined. In this data set, it was determined that data for 10 individuals violated the parametric conditions and hence these data were removed from the data cluster. In the final stage, Mardia's skewness and kurtosis values were examined using Lisrel 9.0 software to test the multivariate normality of the data set. As a result, it was observed that Mardia's assumptions of multivariate normality were confirmed ( $p>$.05). After all these procedures, it was decided to conduct the analysis process based on data from 340 participants. Pearson correlation analysis was conducted to establish whether self-efficacy is related to cyber victimization and cyber bullying behaviour. Then, regression analysis was performed using the bootstrap method to test the moderating role of self-efficacy in the effect of cyber victimization on cyber bullying. Hayes' (38) Process Macro program was utilized to perform the moderation analysis (Model-1).

\subsection{Ethical Approval}

The approval of the ethics committee of the study was obtained from the Ethics Committee of Atatürk University Educational Sciences Unit on 30.03.2020.

\section{RESULTS}

\section{Relationship Between Self-Efficacy and Cyber Victimization and Cyber Bullying, and Descriptive Results}

Pearson correlation analysis was conducted to reveal the level of correlation between self-efficacy, cyber victimization, and cyber bullying scores. In addition, descriptive statistical operations related to variables were completed. Both descriptive and correlation results for the variables are presented in Table 1.

Table 1. Descriptive and correlation results for cyber victimization, cyber bullying, and self-efficacy

\begin{tabular}{|l|c|c|c|c|c|}
\hline Variables & $\mathrm{M}$ & SD & $\begin{array}{c}\text { Self- } \\
\text { Efficacy }\end{array}$ & $\begin{array}{c}\text { Cyber } \\
\text { Victimization }\end{array}$ & $\begin{array}{c}\text { Cyber } \\
\text { Bullying }\end{array}$ \\
\hline Self-Efficacy & 71.63 & 11.04 & 1 & & \\
\hline $\begin{array}{l}\text { Cyber } \\
\text { Victimization }\end{array}$ & 9.25 & 1.88 & $-.15^{*}$ & 1 & \\
\hline $\begin{array}{l}\text { Cyber } \\
\text { Bullying }\end{array}$ & 8.77 & 1.29 & $-.12^{*}$ & $.55^{*}$ & 1 \\
\hline
\end{tabular}

${ }^{*} p<.001$

Examination of Table 1 shows low level, significant negative correlations between self-efficacy with cyber victimization $(r=-.15, p<.001)$ and cyber bullying $(r=-.12, p<.001)$. Further, medium and significant level of positive correlation was observed between cyber victimization and cyber bullying ( $r=$ $.55, \mathrm{p}<.001)$.

\section{Moderating Role of Self-Efficacy}

The effect of self-efficacy in the moderating role between cyber victimization and cyber bullying is shown in Table 2.

Table 2. Moderating role of self-efficacy

\begin{tabular}{|l|c|c|c|c|c|}
\hline Variables & $\mathrm{b}$ & $\mathrm{S} . \mathrm{H}$. & $\mathrm{t}$ & $\mathrm{LLCl}$ & $\mathrm{ULCl}$ \\
\hline Constant & 8.74 & .059 & 149.20 & 8.6 & 8.5 \\
\hline $\begin{array}{l}\text { Cyber- } \\
\text { Victimization (x) }\end{array}$ & .36 & .031 & 11.62 & .30 & .43 \\
\hline Self-Efficacy (w) & -.005 & .005 & -.86 & -.02 & -.01 \\
\hline x.w & -.009 & .003 & -3.26 & -.015 & -.003 \\
\hline
\end{tabular}

$R=.57, R 2=.32,4 ; p<.01, .05$, S.E.: Standard Error; $b:$ unstandardized beta coefficient

According to the results in Table 2, all predictor values included in the regression analysis explain approximately $32 \%\left(R^{2}=.32,4\right)$ of the variation in cyber bullying. Cyber victimization was found to have significant positive effects $(b=.36, p<.01)$ on cyber bullying, while self-efficacy was determined to have significant negative effects $(b=-.005$, $p<.01$ ) on cyber bullying. The cyber victimization and selfefficacy variables were found to have significant interactional effect (moderating effect) on cyber bullying $(b=.-009, p<.05)$.

The effects of the moderation variable as a result of the slope analysis are shown in Figure 1. Details of the moderation effect show that when self-efficacy is low, cyber victimization has a greater effect on cyber bullying. When self-efficacy is high, the effect of cyber victimization on cyber bullying increases, yet this effect is not as strong.

As a result, in the case of low self-efficacy, cyber victimization will have a greater effect on cyber bullying. This finding signifies that the relationship between cyber victimization and cyber bullying is moderated by self-efficacy.

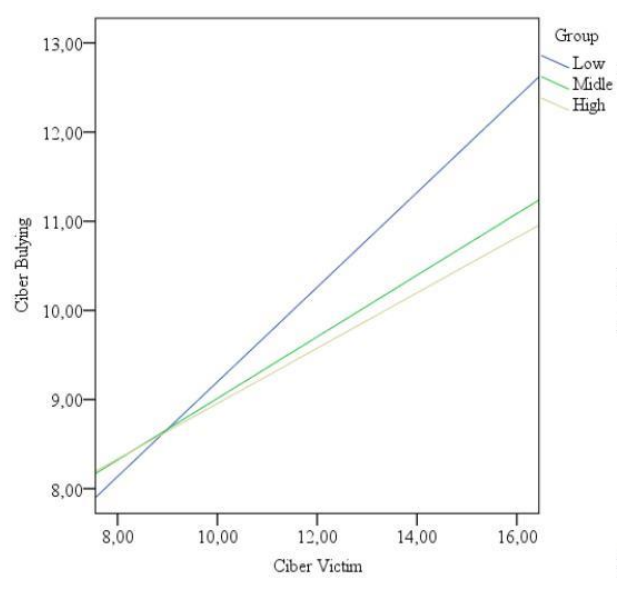

Figure 1. Graphical representation of the moderation effect of selfefficacy 


\section{DISCUSSION}

This study examined the moderation role of self-efficacy between cyber victimization and cyber bullying. In the study, there was a linear relationship between cyber victimization and cyber bullying. It was found that there was a low-level, negative and significant relationship between self-efficacy with cyber victimization and cyber bullying. Another result of the study determined that self-efficacy has a moderation role in the relationship between cyber victimization and cyber bullying.

In the first finding of the study, it was determined that experiencing cyber victimization has a strong relationship in showing cyber bullying behaviors. Exposure to cyber bullying adversely affects social and emotional adaptation of adolescents (39). Individuals who experienced cyber bullying reported feelings of shyness, anger, sadness, disappointment, guilt and helplessness (40). Experiencing such negative emotions leads to an increased desire for revenge (41). The negative emotions experienced may drive the cyber victim to resort to bullying in order to take revenge (42). Patching and Hinduja (34) stated that cyber victims turn into cyber bullies due to their failure to effectively solve social problems and because they process social information in a hostile manner as a result of experiencing negative emotions such as anger. Therefore, it can be thought that experiencing cyber victimization can lead to cyberbullying behaviors.

This study revealed that self-efficacy plays a protective role in preventing cyber victims from becoming cyber bullies. This study found the interaction of cyber victimization with self-efficacy is a significant predictor of cyber bullying. More specifically, individuals with low self-efficacy display more cyber bullying behaviour in comparison to those with high self-efficacy. In other words, adolescents with low selfefficacy who have experienced cyber bullying, are more likely to display cyber bullying behaviour.

These results are compatible with Bandura's (26) social cognitive theory. Social cognitive theory states that selfefficacy beliefs are the basis of individuals' actions. The selfefficacy beliefs affect the behaviour pattern they choose and skills they develop. Self-efficacy levels can lead to healthier behaviour (27). As a result, individuals with high levels of selfefficacy about coping with cyber bullying effectively choose professional behaviour to cope with cyber bullying (43).

In this context, development of self-efficacy among cyber victims protects them from the adverse effects of victimization, and thus, reduces their aggression and prevents them from experiencing feelings of revenge. Bingöl (44) emphasized that having high self-efficacy will decrease cyber bullying. In a study conducted by Nikel (45), individuals with high self-efficacy reported they were able to solve social conflicts without feeling the need to resort to aggression, which supports this conviction. Individuals with high selfefficacy are able to deal with stressful social situations and prefer trusting behaviour as a social strategy $(46,47)$. Selfefficacy prevents negative peer relationships (29), and provides the opportunity for the individual to follow their personal norms in order to regulate their behaviour when faced with peer pressure (48). Furthermore, the finding that individuals with high social self-efficacy receive greater support from their friends when they experience cyber bullying reveals the protective role of self-efficacy $(28,10)$.

\section{CONCLUSIONS}

The results of this study reveal that when their self-efficacy levels are low, adolescents exhibit more cyber bullying behaviour. When the self-efficacy levels of adolescents are high, the effect of cyber victimization on cyber bullying was observed to be a little less strong. This result means that the relationship between cyber victimization and cyber bullying is moderated by self-efficacy.

\section{Limitations and Recommendations}

Despite revealing crucial results, this study has various limitations. First of all, the findings obtained from this study were collected using self-report measuring tools reliant on the participants' perceptions. Therefore, it is recommended that new studies employing different data collection methods be completed. Another limitation of the study is the use of the relational model. Therefore, causal inferences cannot be drawn from this study. Conducting new studies using experimental or longitudinal design will ensure the elimination of this limitation.

Various suggestions can be made in the context of this study. First of all, it was observed that self-efficacy plays a protective role against cyber victims becoming cyber bullies. In this context, psycho-education programs to be applied to cyber victims need to focus on boosting self-efficacy. Secondly, selfefficacy was measured integrally in this study. Later research focusing on the sub-dimensions of self-efficacy, and revealing their role in the relationship between cyber victimization and cyber bullying will be beneficial.

The findings of this research include vital results for school psychological counsellors. This research shows that adolescents exposed to cyber bullying are at risk of becoming cyber bullies. Therefore, school counsellors should take various precautions to prevent them from responding with cyber bullying after they are exposed to cyber bullying.

One of these precautions is to increase the self-efficacy of students. This research shows that individuals with high levels of self-efficacy can easily cope with the negative results of being exposed to cyber bullying. Therefore, school counsellors should develop programmes to increase the selfefficacy of students exposed to cyber bullying and should play a role during the implementation period.

\section{Conflict of interest}

The authors do not have any conflict of interest to disclose 


\section{REFERENCES}

[1] Lapierre KR, Dane AW. Social advantages and disadvantages associated with cyber aggression-victimization: A latent class analysis. Computers in Human Behavior 2020; 113, 106497.

[2] Crone EA, Konijn EA. Media use and brain development during adolescence. Nature Communications 2018; 9(1): 588-598.

[3] Patchin JW, Hinduja S. Trends in online social networking: Adolescent use of MySpace over time. New Media Society 2010; 12:197-216.

[4] Smith PK, Del-Barrio C, Tokunaga RS. Definitions of bullying and cyberbullying: how useful are the terms? In Bauman $\mathrm{S}$, Cross D, \& Walker J, eds. Principles of cyberbullying research: Definition, methods, and measures. 2013; New York: Routledge, pp. 26-40.

[5] Islam MI, Khanam R, Kabir E. Bullying victimization, mental disorders, suicidality and self-harm among Australian high school children: Evidence from nationwide data. Psychiatry Research 2020; 292: 113364.

[6] Modecki KL, Minchin J, Harbaugh AG, Guerra NG, Runions KC. Bullying prevalence across contexts: A meta-analysis measuring cyber and traditional bullying. Journal of Adolescent Health 2014; 55(5): 602-611.

[7] Hemphill SA, Tollit M, Kotevski A, Heerde J. Predictors of traditional and cyber-bullying victimization: A longitudinal study of Australian secondary school students. Journal of Interpersonal Violence 2015; 30(15): 2567-259.

[8] Jadambaa A, Thomas H, Scott J, Graves N, Brain D, Pacella R. Prevalence of traditional bullying and cyberbullying among children and adolescents in Australia: A systematic review and meta-analysis. Australian and New Zealand Journal of Psychiatry 2019; 53(9): 878-888.

[9] McKenna KY. Influences on the nature and functioning of online groups. In A. Barak (Ed.), Psychological aspects of cyberspace: Theory, research and applications (pp. 228-242). 2008; New York, NY: Cambridge University Press.

[10] Olenik-Shemesh D, Heiman, T. Cyberbullying victimization in adolescents as related to body esteem, social support, and social self-efficacy. The Journal of Genetic Psychology 2017; 178 (1): 28-43.

[11] Bannink R, Broeren S, van de Looij-Jansen PM, de Waart FG, Raat $\mathrm{H}$. Cyber and traditional bullying victimization as a risk factor for mental health problems and suicidal ideation in adolescents. PloS One 2014; 9(4): e94026.

[12] Gini G, Card NA, Pozzoli T. A meta-analysis of the differential relations of traditional and cyber-victimization with internalizing problems. Aggressive Behavior 2018; 44(2); 185 198.

[13] Bonanno R A, Hymel S. Cyber bullying and internalizing difficulties: Above and beyond the impact of traditional forms of bullying. Journal of Youth and Adolescence 2013; 42: 685-697.

[14] Przybylski AK, Bowes L. Cyberbullying and adolescent wellbeing in england: A population-based cross-sectional study. Lancet Child Adolesc Health 2017; 1: 19-26.

[15] Kowalski RM, Giumetti GW, Schroeder AN, Lattanner MR. Bullying in the digital age: A critical review and meta-analysis of cyberbullying research among youth. Psychological Bulletin 2014; 140(4): 1073-1137.

[16] Bauman S, Toomey RB, Walker JL. Associations among bullying, cyberbullying, and suicide in high school students. Journal of Adolescence 2013; 36(2): 341-350.
[17] Wong DW, Chan H, Cheng CK. Cyberbullying perpetration and victimization among adolescents in Hong Kong. Children and Youth Services Review 2014; 36:133-140.

[18] Leung ANM, Wong N, Farver J. Cyberbullying in Hong Kong Chinese students: Life satisfaction, and the moderating role of friendship qualities on cyberbullying victimization and perpetration. Personality and Individual Differences 2018; 133: 7-12.

[19] Quintana-Orts C, Rey L. Forgiveness and cyberbullying in adolescence: Does willingness to forgive help minimize the risk of becoming a cyberbully? Computers in Human Behaivor 2018; 81: 209-214.

[20] Hood M, Duffy AL. Understanding the relationship between cyber-victimisation and cyber-bullying on Social Network Sites: The role of moderating factors. Personality and Individual Differences 2018; 133:103-108.

[21] Ayas T. Investigation of the relationship between self-respect and extraversion of students who are involved in virtual bullying and do not confuse. Education and Science 2016; 41(186): 205-216.

[22] Akbulut $Y$, Eristi B. Cyberbullying and victimisation among Turkish university students. Australasian Journal of Educational Technology 2011; 27(7): 1155-1170.

[23] Erdur-Baker Ö. Cyberbullying and its correlation to traditional bullying, gender and frequent and risky usage of internetmediated communication tools. New Media Society 2010; 12(1): 109-125.

[24] Peker A. Investigating the predictive role of negative affect on cyber bullying and victimization. Kastamonu Education Journal 2015; 23(4): 1633-1646.

[25] Taştekin E, Bayhan P. Examination of cyber bullying and victimization among adolescents. Online Journal of Technology Addiction Cyberbullying 2018; 5(2): 21-45.

[26] Bandura A. Social foundations of thought and action: A social cognitive theory. Englewood Cliffs 1986; NJ: Prentice-Hall.

[27] Bandura A. Self-efficacy. In V. S. Ramachaudran (Ed.), Encyclopedia of human behavior (vol. 4, pp. 71-81). New York, NY: Academic Press Reprinted in H. Friedman [Ed.]. 1997. Encyclopedia of mental health. San Diego: Academic Press.

[28] Barchia K, Bussey K. The psychological impact of peer victimization: Exploring social cognitive mediators of depression. Journal of Adolescence 2010; 33: 615-623.

[29] Erath SA, Flanagan KS, Bierman KL, Tu KM. Friendships moderate psychosocial maladjustment in socially anxious early adolescents. Journal of Applied Developmental Psychology 2010; 31: 15-26.

[30] Trompeter N, Bussey K, Fitzpatrick S. Cyber victimization and internalizing difficulties: The mediating roles of coping selfefficacy and emotion dysregulation. Journal of Abnormal Child Psychology 2018; 46: 1129-1139.

[31] Bussey K, Fitzpatrick S, Raman A. The role of moral disengagement and self-efficacy in cyberbullying. Journal of School Violence 2015;14: 30-46.

[32] Heiman T, Olenik-Shemesh D, Eden S. Aggressive behavior and vulnerability on the Internet: Characteristics, patterns, risk and protective factors among children and adolescents (Research Report). Jerusalem, Israel: The Israeli Ministry of Education. Retrieved from $2014 \mathrm{http}: / / \mathrm{cms}$.education. gov.il/NR/rdonlyres/5B2E6358-A9D7-4F8B-83A2E1F46CB4DF94/185400/Unnamed6.pdf. 
[33] AkS,OzdemirY,KuzucuY.Cybervictimizationandcyberbullying: The mediating role of anger, don't anger me! Computers in Human Behavior 2015; 49: 437-443.

[34] Patchin JW, Hinduja S. Traditional and nontraditional bullying among youth: A test of general strain theory. Youth \& Society 2011; 43(2): 727-751.

[35] Çelikkaleli Ö, Gündoğdu M, Kıran-Esen B. Competency expectation scale in adolescents: Validity and reliability study of Turkish adaptation. Educational Research 2006; 25: 62-72.

[36] Hinduja S, Patchin JW. Cyberbullying: An exploratory analysis of factors related to offending and victimization. Deviant Behavior 2008; 29: 129-156.

[37] Ozdemir M, Akar F. Investigation of high school students' views on cyberbullying in terms of some variables. Educational Administration: Theory and Practice 2011; 17(4): 605-626.

[38] Hayes AF. Introduction to mediation, moderation, and conditional process analysis: A regression-based approach. 2018; New York: The Guilford Press.

[39] Elipe P, Mora-Merchan JA, Ortega-Ruiz R, Casas JA. Perceived emotional intelligence as a moderator variable between cybervictimization and its emotional impact. Frontiers in Psychology 2015; 6: 1-11.

[40] Hinduja S, Patchin JW. Offline consequences of online victimization: School violence and delinquency. Journal of School Violence 2007; 6(3): 89-112.
[41] Worthington E. Forgiveness and reconciliation: Theory and application. 2006; New York: Routledge.

[42] Konig A, Gollwitzer M, Steffgen G. Cyberbullying as an act of revenge? Australian Journal of Guidance and Counselling 2010; 20: 210-224.

[43] Clark M, Bussey K. The role of self-efficacy in defending cyberbullying victims. Computers in Human Behavior 2020; 109: 106340.

[44] Bingöl TY. Determining the predictors of self-efficacy and cyber bullying. International Journal of Higher Education 2018; 7(2): 138-143.

[45] Nikel L. Submissiveness, assertiveness, and agressiveness in school-age children: The role of self-efficacy and Big Five. Children and Youth Servicess Review 2020; 110: 1-6.

[46] Buser TJ, Peterson CH, Kearney A. Self-efficacy pathways between relational aggression and nonsuicidal selfinjury. Journal of College Counseling 2015; 18(3): 195-208.

[47] Hipson WE, Coplan RJ, Séguin DG. Active emotion regulation mediates links between shyness and social adjustment in preschool. Social Development 2019; 28(4): 893-907.

[48] Li L, Peng Z, Lu L, Liao H, H Li. Peer relationships, self-efficacy, academic motivation, and mathematics achievement in Zhauang adolescents: A moderated-mediation model. Children Youth Services Review 2020; 118: 1-8.

How to cite this article: Peker A, Eroglu Y, Nebioglu Yildiz M. Does High Self-Efficacy in Adolescents Minimize Cyber Bullying Behaviour?. Clin Exp Health Sci 2021; 11: 140-145. DOI: 10.33808/clinexphealthsci.864038 